\title{
Collaboration to Support the Commercialization of Polytechnic Research Products in Indonesia: Potential and Challenges
}

\author{
Carolina M Lasambouw, ${ }^{1)}$ Ediana Sutjiredjeki ${ }^{2)}$, and Neneng Nuryati ${ }^{3)}$ \\ ${ }^{I}$ General Study Unit, Politeknik Negeri Bandung, Indonesia. \\ ${ }^{2}$ Electro Department, Politeknik Negeri Bandung, Indonesia. \\ ${ }^{3}$ General Study Unit, Politeknik Negeri Bandung, Indonesia.
}

\begin{abstract}
For a long time, it was believed that universities play a critical role in the national research capacity. Despite the government's allocation of research grants to universities in developing countries such as Indonesia is relatively low, research has been positioned as an investment which is ultimately directed towards the commercialization of the products it produces. Polytechnic as vocational higher education has quite a number of appropriate technology products that have the potential to be commercialized. However, currently, the number of products that have been commercialized is still low. Collaboration as one of the criteria for measuring the reputation of universities is expected to be one of the strategies to overcome this. The challenge is a collaboration with who and what can be built so that commercialization of innovative products from Polytechnic academics succeed. This paper presents the current condition regarding the efforts of the Polytechnic in increasing collaboration to support the commercialization of its research products. Quantitative and exploratory studies carried out at three Polytechnics show the high potential for collaboration to commercialize research products. However, it must be done by implementing various strategies so that collaboration can be sustainable. Collaboration can encourage synergies between education, research, and community services which are the main tasks of higher education. The main challenge is the availability of a financial management system that can support the smooth commercialization of research products.
\end{abstract}

Keywords: Research Product, Polytechnic, Collaboration, Commercialization 